\title{
Research on Sales Strategy Based on Supermarket Pipeline Data
}

\author{
Shaoyong Hong, Chun Yang*, Hongwei Wen \\ Huashang College, Guangdong University of Finance \& Economics, Guangzhou, China \\ Email: shy2002021@163.com, ^michael_0227@126.com,whworange@126.com
}

How to cite this paper: Hong, S.Y., Yang, C. and Wen, H.W. (2020) Research on Sales Strategy Based on Supermarket Pipeline Data. Journal of Data Analysis and Information Processing, 8, 99-109.

https://doi.org/10.4236/jdaip.2020.83006

Received: April 16, 2020

Accepted: June 29, 2020

Published: July 2, 2020

Copyright (อ 2020 by author(s) and Scientific Research Publishing Inc. This work is licensed under the Creative Commons Attribution International License (CC BY 4.0).

http://creativecommons.org/licenses/by/4.0/

\begin{abstract}
"Low profit and high sales" is a strategy to increase sales volume by reducing the profit of unit goods, so that businesses can gain more profits. For flexible goods, price reduction can increase the total revenue, but when the goods are lack of flexibility, price reduction will reduce the total revenue. In this paper, according to the sales data provided by a supermarket, we preprocess the data, establish appropriate indicators to measure the daily discount strength of the mall, and establish a mathematical model between the discount strength, sales and profit margin. Through these models, we found that meager profits do bring up sales, but too low discounts can also hurt total profits. In addition, when shopping malls implement discount promotions, they will also bring some negative effects, and we give some suggestions for this.
\end{abstract}

\section{Keywords}

Low Profit and High Sales, Profit Margin, Discount Rate, Price Elasticity of Demand

\section{Introduction}

With the rapid development of the market economy, the retail market is maturing and the market competition is becoming fiercer. In order to maintain or expand market share, companies often use some marketing strategies [1]. Many people have studied the policy of small profits but quick turnover. From the perspective of market laws, Yan Xiao and Decai Zhou discussed many factors that should be considered when implementing the strategy of low profits and quick turnover, see [2] [3]. Bisheng Tu used the price elasticity of demand to explain the two levels of constraints for the implementation of small profits but quick sales, see [4]. Chunmei Li used the sales price balance strategy with zero 
margin difference to provide scientific guidance for enterprises to adopt small profits and quick sales strategies, see [5]. Xianguo Li, Xiabo Liu and Lijun Zhong analyzed the two sales strategies of discounted and non-discounted, and discussed how shopping malls properly use discount strategies to truly attract customers, see [6] [7] [8]. Yang Lin, Zhibo Zhang and Zhihui Han discussed how to achieve higher profits by improving the competitiveness of the brand during the process of discount promotion, see [9] [10] [11]. By analyzing the cost and profit of pawn industry, Yong Yang can understand the reason of the decline of modern pawn industry more deeply, see [12]. Shengmin Huang, Jian Xiang and Jiliang Du studied the shopping mall's evaluation of customers' purchasing power and the reconstruction of marketing strategies in a big data environment, see [13] [14] [15]. The principle of "small profits but quick turnover" is suitable for all areas of business management. In terms of product sales factors, it can not only enable products to enter the buyer's market briskly, provide effective supply, serve the society, and produce comprehensive benefits of products. It can promote the full play of enterprise productivity, increase production, accelerate capital turnover, and revitalize production funds. It is an effective management method to increase enterprise profitability. But we all know that different commodities have different sensitivity to price changes. When the change in sales volume is greater than the change in price, then the price reduction will increase the total revenue. When the change in sales volume is less than the change in price, the price reduction will reduce the total income. When the change in sales volume is equal to the change in price, the price reduction has little effect on the total revenue.

This paper analyzes the sales record, discount information table and commodity information table of a large supermarket in the past two years to establish the relationship between the supermarket's sales volume, profit margin and the intensity of commodity discount. There are also many negative effects when shopping malls implement discount promotion activities. Therefore, when formulating the strategy of low profit and high turnover, the shopping malls should consider all kinds of influencing factors comprehensively, and try to achieve high profit and low profit and high turnover as much as possible.

\section{Data and Processing Methods}

As the data we got is a large amount of running water data of the supermarket, which contains a large number of unfinished order data, this part of data should be deleted. For ease of calculation, let's assume a profit margin of 30\% and fill in the missing cost price of non-discounted items.

$$
C_{i}=\frac{B p_{i}}{1+30 \%}
$$

where $C_{i}$ represents the cost of the $i$-th commodity (non-discounted) and $B p_{i}$ is the list price of the $i$-th commodity.

In the pipeline data, we found that some sales are showing negative numbers, 
and we think that this part of the goods is returned. Sort the corresponding data and then use the final data to get the daily turnover $R$ :

$$
R=\sum_{i=1}^{n} S p_{i} \cdot Q_{i}
$$

Daily profit $L$ :

$$
L=\sum_{i=1}^{n}\left(S p_{i}-C p_{i}\right) \cdot Q_{i}
$$

Daily profit margin $r_{L}$ :

$$
r_{L}=\frac{L}{R-L}
$$

Daily discount rate $r_{D}$ :

$$
r_{D}=\frac{\sum_{i=1}^{n} B p_{i}-\sum_{i=1}^{n} S p_{i}}{\sum_{i=1}^{n} B p_{i}}
$$

where $B p_{i}$ represents the price of the $i$-th commodity, $S p_{i}$ represents the selling price of the $i$-th commodity, and $Q_{i}$ represents the sales volume of the $i$-th commodity.

Using the above calculation formula, the statistical data is shown in Figure 1.

Due to the large amount of data involved in this paper, in order to more intuitively illustrate the issue of whether small profit has more sales, we have selected the top 10 and bottom 10 data of turnover, profit margin and discount rate (see Figures 2-4).

It can be seen from Figure 2 that turnover and profit are positively correlated.

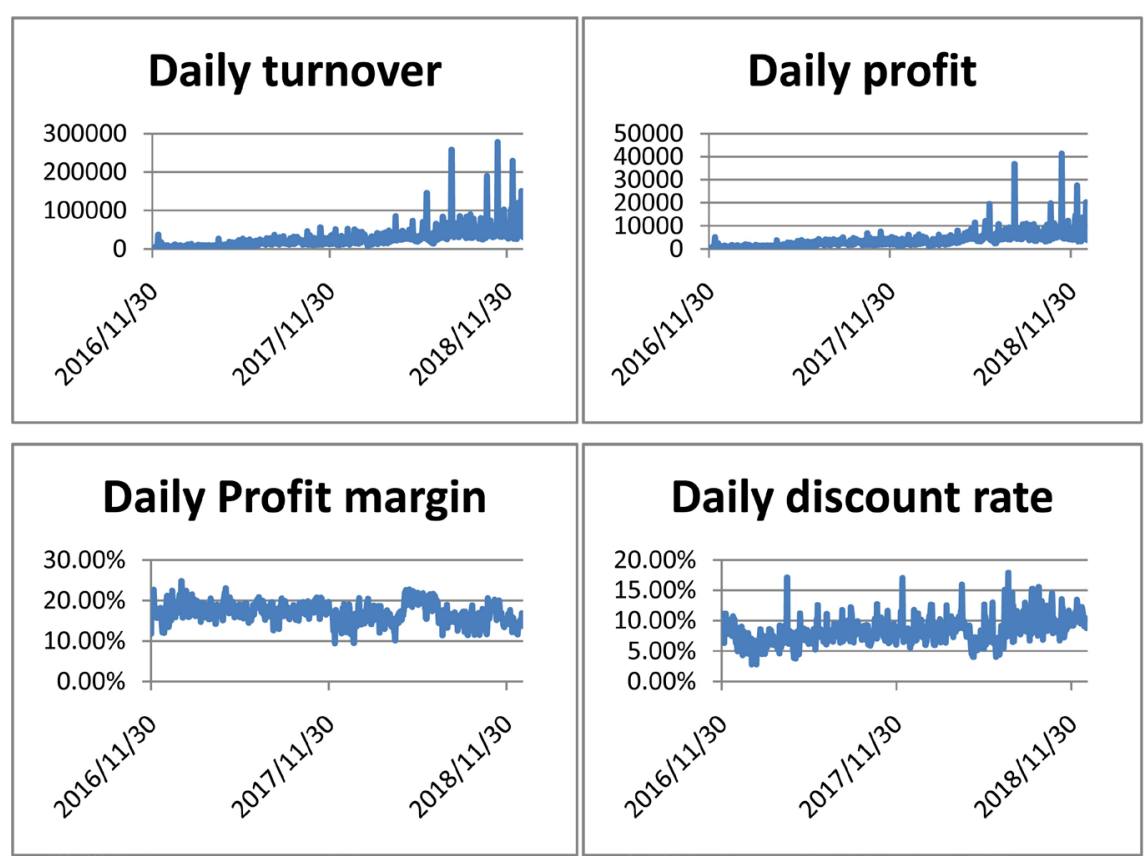

Figure 1. Daily turnover, daily profit, daily profit margin and daily discount rate. 


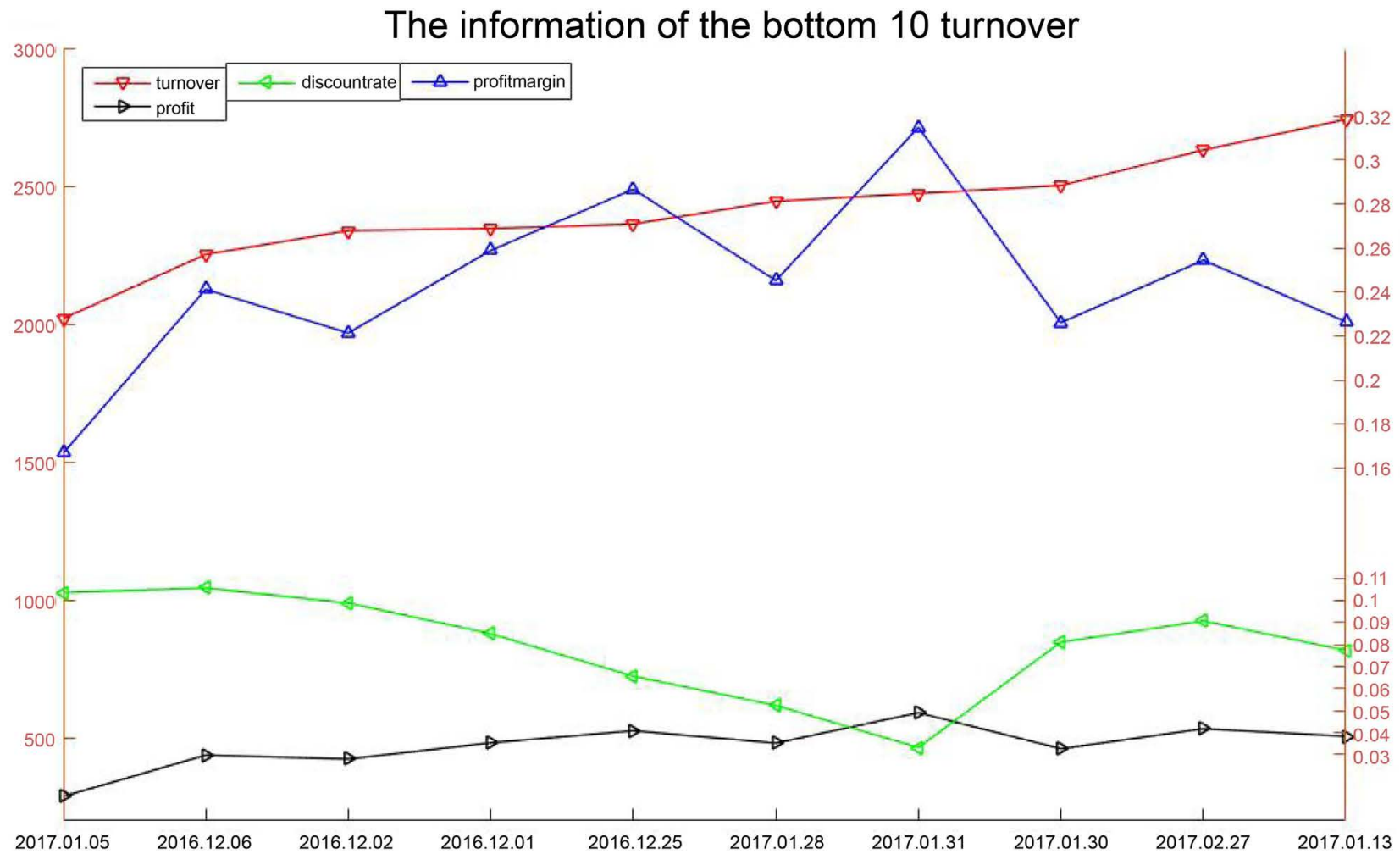

The information of the bottom 10 turnover

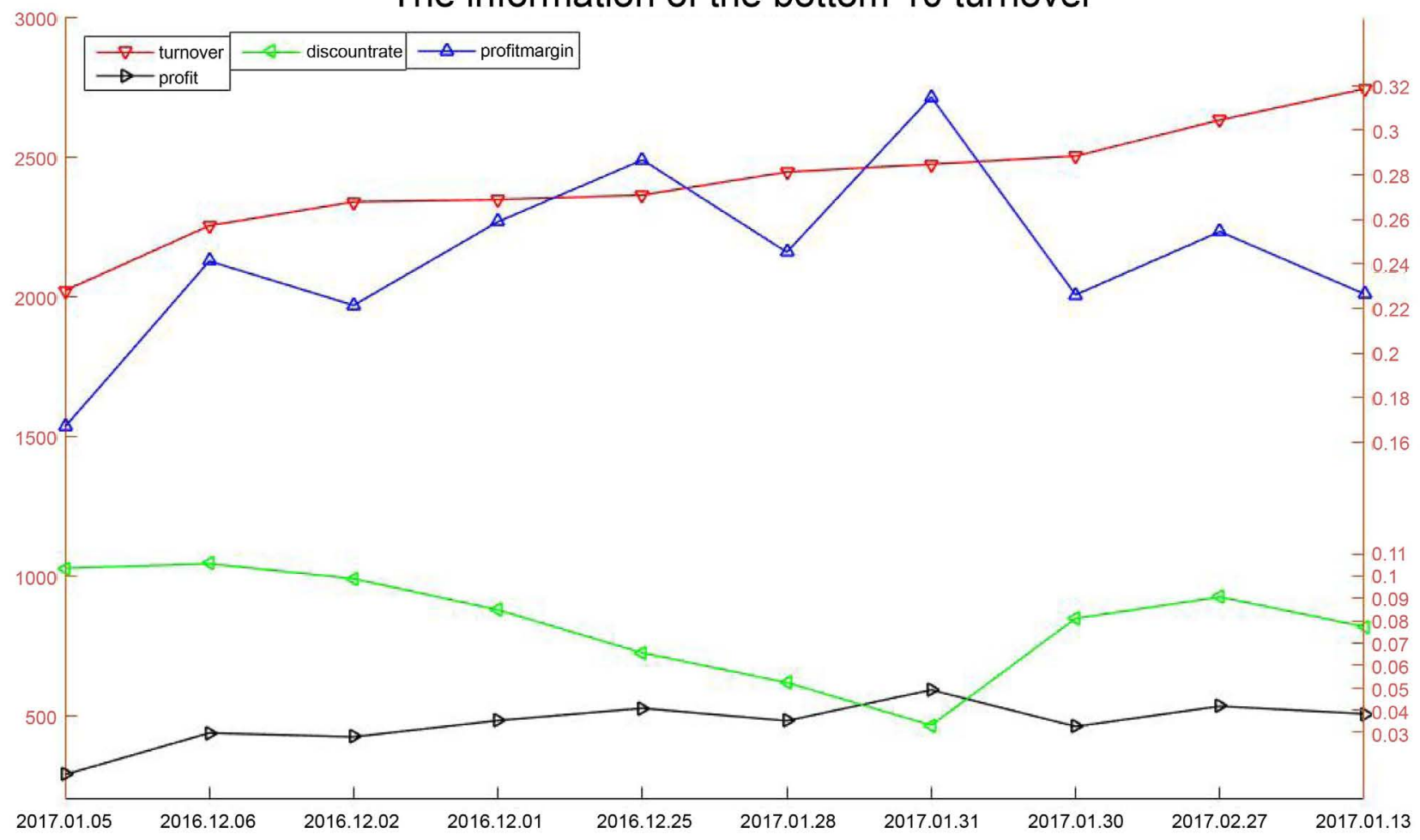

Figure 2. Information on the top 10 and bottom 10 in turnover.

When the turnover is high, the profit is high, but the profit rate and discount rate are at a medium level. The turnover is also related to a specific date, such as 

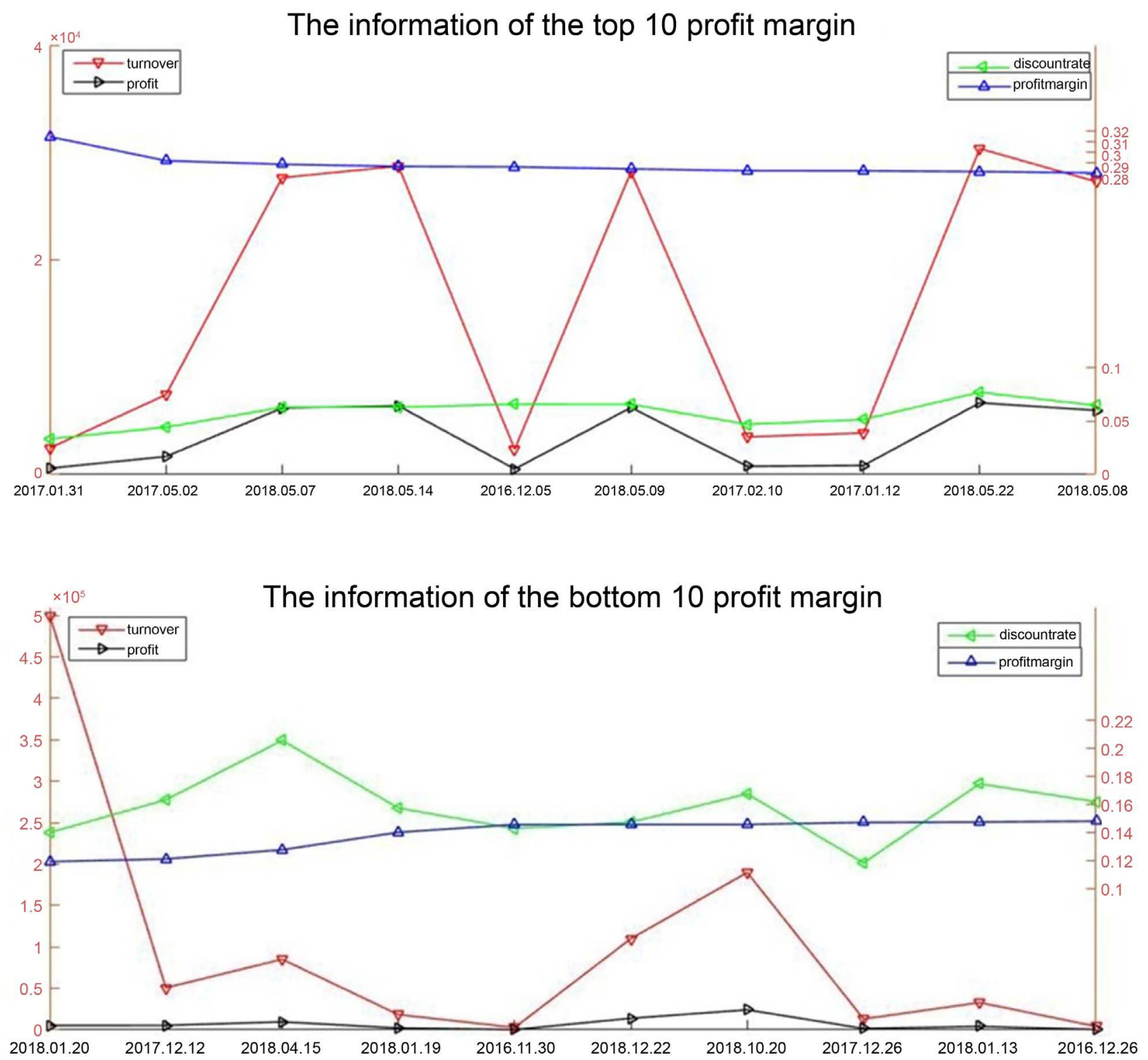

Figure 3. Information on the top 10 and bottom 10 of the profit margin.

$6.18,11.1112 .12 \ldots$ When the turnover is low, the profit and discount rate are low, but the profit rate is high. Comparing the data of the top 10 and the bottom 10 , we can conclude that more sales can be more profitable.

It can be seen from Figure 3: The profit margin is inversely related to the discount rate. When the profit rate is high, the discount rate is generally low, and the turnover and profit are not high. When the profit rate is low, the discount rate is average, but the turnover and profit are not low. Comparing the data of the top 10 and the bottom 10, we can conclude that small profits but quick turnover is possible.

As can be seen from Figure 4, the discount rate is negatively correlated with the profit rate. When the discount rate is high, the profit margin is average, and the turnover and profit are not high. When the discount rate is low, the profit 

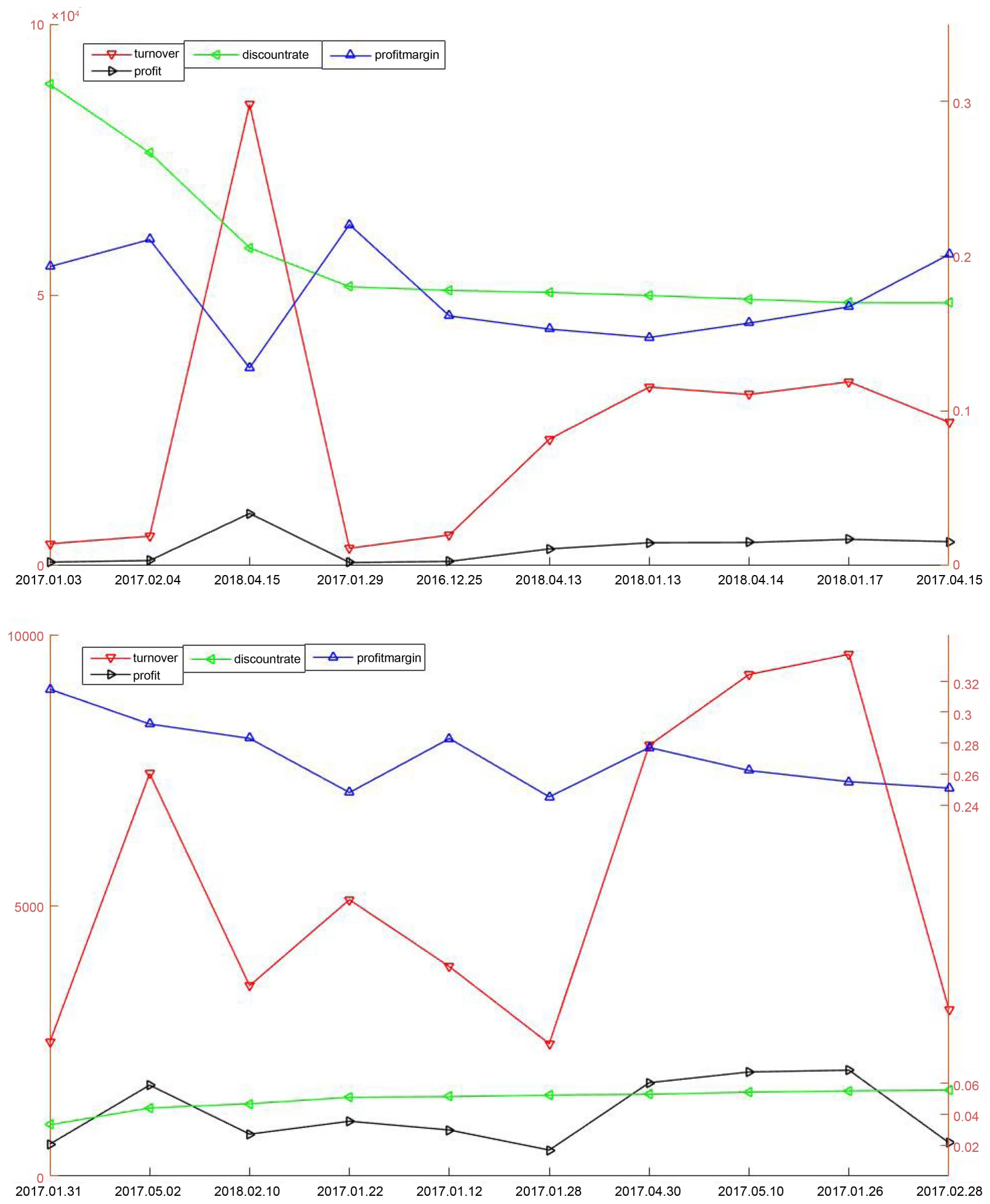

Figure 4. Information on the top 10 and bottom 10 of the discount rate.

margin is high, but the turnover and profit are not engaged. Comparing the data of the top 10 and the bottom 10, we can conclude that small profits are not nec- 
essarily overselling.

\section{Analysis and Discussion}

In order to better illustrate the relationship between turnover, discount rate and profit margin, we establish the regression model of discount rate and turnover and the linear regression model of discount rate and profit margin respectively according to the data in the statistical table.

It can be seen from Table 1 that both the regression coefficient and the regression equation have passed the test, but the correlation coefficient is low. Scatter plot and regression line are shown in Figure 5.

The second is between the discount rate and the profit margin.

It can be seen from Table 2 that both the regression coefficient and the regression equation have passed the test. Scatter plot and regression line are shown in Figure 6.

In order to specify more accurately whether a commodity has a small profit and a large quantity of sales, we introduce a price bullet in terms of the concept of sex, we divided the goods offered by supermarkets into two categories: elastic and elastic. Through the analysis, we come to the conclusion that for goods with high elasticity, the greater the discount, the higher the sales volume, but the faster the profit margin of the goods declines. For goods with low elasticity, the change of discount intensity has a small impact on sales, and the increase of

Table 1. Correlation test between discount rate and turnover.

\begin{tabular}{lcccc}
\hline \multicolumn{3}{c}{ Regression coefficient } & & \\
\hline & Estimated value & standard error & T statistic & $\operatorname{Pr}()>|t|$ \\
\hline Constraint item & -6.034 & 2.489 & -2.425 & 0.0156 \\
Regression coefficient is & 282.016 & 22.480 & 12.545 & $<2 \mathrm{e}-16$ \\
\hline Regression equation test & & & \\
\hline Standard error: 16.02 & & & \\
$R^{2}: 0.175$, Modified $R^{2}: 0.174$ & & \\
F statistics: 157.4 , p-value: $2.2 \mathrm{e}-16$ & & \\
\hline
\end{tabular}

Table 2. Correlation test between discount rate and profit rate.

\begin{tabular}{lcccc}
\hline Regression coefficient & & & \\
\hline & Estimated value & standard error & T statistic & $\operatorname{Pr}()>|t|$ \\
\hline Constraint item & 0.034 & 0.003 & 105.18 & $<2 \mathrm{e}-16$ \\
Regression coefficient & -0.834 & 0.026 & -32.05 & $<2 \mathrm{e}-16$ \\
\hline Regression equation test & & & \\
\hline Standard error: 0.0191 & & & \\
$R^{2}: 0.5744$, Modified & $R^{2}: 0.5738$ & & \\
F statistics: $1027, \mathrm{p}$-value: $2.2 \mathrm{e}-16$ & & \\
\hline
\end{tabular}




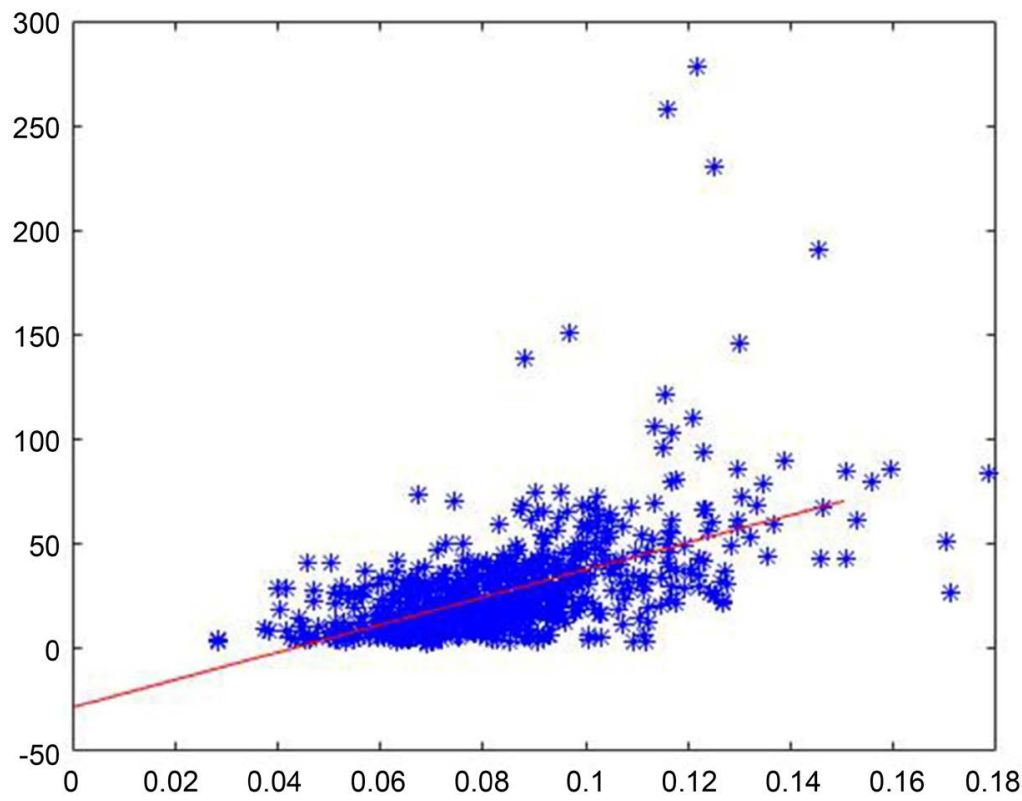

Figure 5. Diagram of discount rate and turnover.

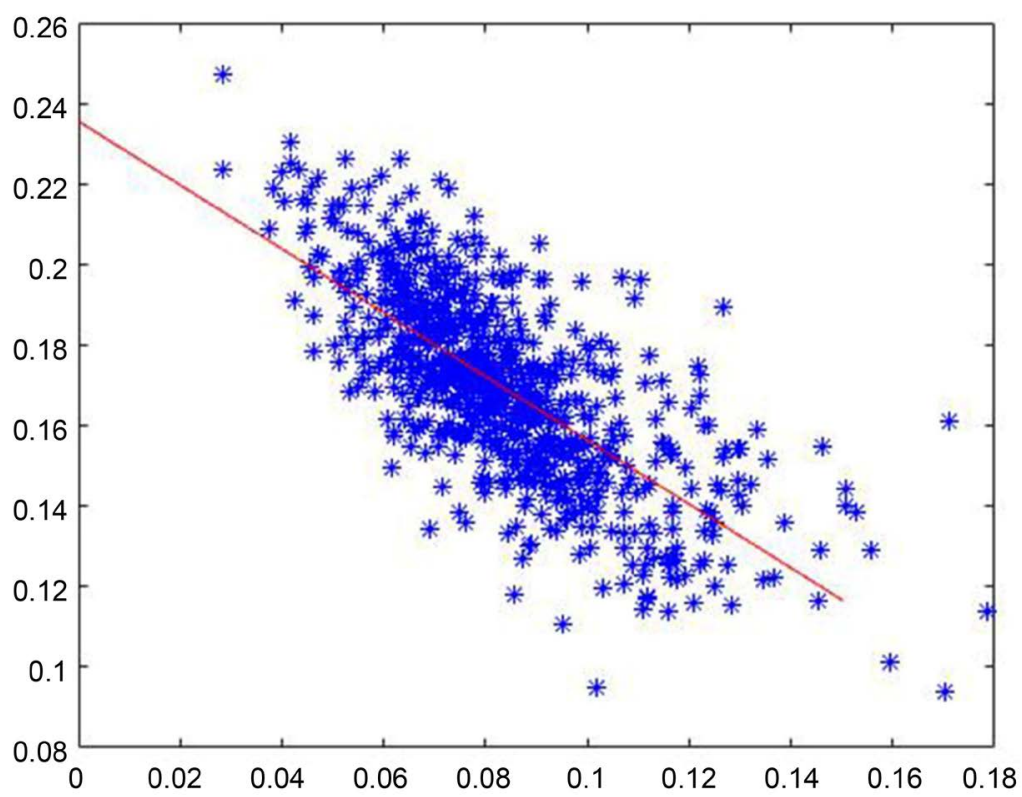

Figure 6. Diagram of discount rate and profit margin.

discount intensity will reduce the profit margin correspondingly, but the range is small.

Here we take the grain, oil and non-staple food with the largest amount of commodities as an example, and first calculate the correlation coefficient between each factor.

It can be seen from Table 3 that the correlation coefficient between the turnover and the discount rate is 0.028 . We can think that the turnover of cereals, oils and non-staple foods is not related to the discount rate.

It can be seen from Table 4 that neither the regression coefficient nor $R^{2}$ 
Table 3. Correlation coefficient between various factors.

\begin{tabular}{ccccc}
\hline & Turnover & profit & profit margin & discount rate \\
\hline Turnover & 1.000 & 0.8735 & -0.071 & 0.028 \\
Profit & 0.873 & 1.000 & 0.055 & -0.094 \\
Profit margin & -0.071 & 0.0552 & 1.000 & -0.827 \\
Discount rate: & 0.028 & -0.094 & -0.827 & 1.000 \\
\hline
\end{tabular}

Table 4. Relevant inspection of the turnover and discount rate of grain and oil non-staple food commodities.

\begin{tabular}{|c|c|c|c|c|}
\hline \multicolumn{5}{|l|}{ Regression coefficient } \\
\hline & Estimated value & standard error & T statistic & $\operatorname{Pr}()>|t|$ \\
\hline Constraint item & 3.611 & 0.556 & 6.494 & $1.3 \mathrm{e}-10$ \\
\hline Regression coefficient & 3.435 & 3.765 & 0.912 & 0.362 \\
\hline \multicolumn{5}{|l|}{ Regression equation test } \\
\hline \multicolumn{5}{|l|}{ Standard error: 14.33} \\
\hline \multicolumn{5}{|c|}{$R^{2}: 0.0008$, Modified $R^{2}: 0.00016$} \\
\hline F statistics: $0.832, \mathrm{p}$-val & 0.3618 & & & \\
\hline
\end{tabular}

can pass the test, Therefore, grain and oil non-food commodities do not have the phenomenon of small profits but quick sales, because grain and oil non-food commodities are rigid demand products.

Frequent price promotion activities make consumers less sensitive to promotional activities. The greater the discount promotion, the less consumers have confidence in shopping. Shopping malls are noisy and crowded during discounts in large shopping malls. Everywhere is overcrowded, and the cash register is lined up. Shopping has become a painful burden. Consumers don't have enough time to choose products or have impulsive shopping desires due to group effects, and buy some undesirable and unsuitable products. The return of these commodities is another major problem that plagues consumers. Specials and gifts are either non-refundable or non-replaceable. Consumers have lost their rights. Consumer shopping satisfaction has declined. Frequent price promotions will also damage the brand value of the mall and increase operating costs.

\section{Conclusion}

This article is based on a large number of pipeline data provided by supermarkets, the data are cleaned and completed. We calculate the daily turnover, profit, profit margin and discount rate of the supermarket, explore the correlation between them and build the corresponding model. The results show that the discount rate has a significant relationship with sales volume and profit margin. The lower the profit margin of the commodity, the more quantity is sold, so that the higher sales can be obtained. This explains the principle of small profits and quick turnover. In this way, businesses can occupy a larger market and speed up 
capital turnover, which is also an effective way to increase profits. In response to the negative impact of discounted promotional activities, shopping malls should strive to enhance brand value, improve the shopping environment, and optimize their product mix. Only if the mall has a high degree of recognition can it preserve and increase its market share. This article uses a simpler modeling method. In the future, you can try some other data processing methods to get a more accurate model. It can better provide data support for the formulation of shopping mall promotion strategies.

\section{Funding}

This work is supported by the Scientific Project of Huashang College Guangdong University of Finance \& Economics under Grant NO. 2019HSDS25.

\section{Conflicts of Interest}

The authors have declared no competing interests.

\section{References}

[1] Evgeniya, P. (2016) Research on the Marketing Strategy of Chinese Goods in the Russian Market. China Management Informationization, No. 19, 148-149.

[2] Xiao, Y. (1999) Small Profit Market. Cooperative Economy and Technology, No. 5, 37.

[3] Zhou, D.C. (2000) Enterprises Should Correctly Use the Strategy of Small Profits But Quick Turnover. East China Economic Management, No. 1, 66-67.

[4] Tu, B.S. (2001) Demand Price Elasticity Restricts Small Profits But Quick Turnover. Commercial Research, No. 3, 161-162.

[5] Li, C.M. (2005) Using Sales Price Balance Analysis to Assist Small Profits but Quick Turnover Strategy. Journal of Shandong Institute of Industry and Commerce, No. 4, 75-78.

[6] Li, X.G. and Ren, X.Y. (2002) How to Use Discount Promotion. SME Technology, No. 12, 2.

[7] Liu, X.B. and Qi, L. (2004) Thoughts on Discounting and Non-Discounting of Commodities. Price Theory and Practice, No. 1, 58-59.

[8] Zhong, L.J. (2009) Negative Effects and Countermeasures of Discount Sales in Large Shopping Malls. Shopping Mall Modernization, No. 31, 1.

[9] Yang, L. and Zhou, Y.C. (2008) Analyze the Brand Competitiveness of Enterprises from the Management Ideas of Small Profits but Quick Turnover. Silicon Valley, No. 3, 90-95.

[10] Zhang, Z.B. (2011) Research on Marketing Channels of Modern Enterprises. Theoretical Observation, No. 5, 65-66.

[11] Han, Z.H. (2017) How Many Chinese Enterprises Have Been Killed by Small Profits but Quick Sales. Sales and Marketing, No. 1, 42-44.

[12] Yang, Y. (2011) The Turnover and Profit Margin of Modern Jiangnan Pawnbroking. Journal of Jiangxi University of Finance and Economics, No. 2, 96-101.

[13] Huang, S.M. and Liu, S. (2012) Deconstruction and Reconstruction of Marketing System under the Background of "Big Data". Modern Communication, No. 11, 
13-20.

[14] Xiang, J. (2017) Design and Implementation of Fresh Food Supermarket Business System Based on Data Analysis. Jilin University, Changchun.

[15] Du, J.L. (2019) Shopping Mall Member Purchasing Power Evaluation Model Based on Big Data and AHP. Information Technology and Informatization, No. 5, 111-113. 